\title{
Synthesis and Characterization of Poly (N-Isopropylacrylamide) ZnO Nanocomposites for Textile Applications
}

\author{
V. Sorna gowri ${ }^{1}$, Sunil Kumar Sanghi ${ }^{2}$, S.S.Amritphale ${ }^{3}$, Noémia Carneiro ${ }^{4}$, Pedro \\ Souto ${ }^{5}$ and Sandra Ventura ${ }^{6}$ \\ ${ }^{1,2,3}$ Advanced Materials and Processes Research Institute (CSIR), Habibganj Naka, Bhopal, India \\ ${ }^{4,5,6}$ Department of Textile Engineering, University of Minho, Guimarães, Portugal
}

Correspondence should be addressed to: V. Sorna gowri; gowrisorna@yahoo.com

Received date: 5 June 2014 ; Accepted date: 9 September 2014; Published date: 25 February 2016

Copyright (c) 2016. V. Sorna gowri, Sunil Kumar Sanghi, S.S.Amritphale, Noémia Carneiro, Pedro Souto and Sandra Ventura. Distributed under Creative Commons CC-BY 4.0

\begin{abstract}
High performance polymers exhibiting multifunctional characteristics can be achieved by the introduction of inorganic nanoparticles like $\mathrm{ZnO}$ (Zinc oxide) into the functional polymers. In the present work a copolymer epoxy poly (dimethylacrylamide) was synthesized to disperse the $\mathrm{ZnO}$ nanoparticles. The aim of the work is to develop a new method/process/material for the dispersion of nanoparticles and evaluation of the performance of these composites. FT-IR studies of the polymer adsorbed $\mathrm{ZnO}$ nanoparticles confirmed that the polymer molecules chain were anchored on the surface of the $\mathrm{ZnO}$ nanoparticles. The improved interfacial interaction between the particles and polymer enhanced the thermal properties of the composites. The results also show that the newly prepared polymer composite matrix uniformly has the ability to disperse the $\mathrm{ZnO}$ nanoparticles well as evidenced by SEM analysis, and the particles almost remain in their original shape and size even after incorporation into the polymer matrix. Nevertheless, it was also found by dynamic light scattering analysis that the mean particle size of the dispersion was increased with increasing $\mathrm{ZnO}$ content. The results were consistent with SEM observations. The value of zeta potential results, show how the Poly (N-isopropylacryl amide (PNIPAM) can adsorb onto the $\mathrm{ZnO}$ nanoparticles and impart - ve charge to the surface of the nanoparticles.
\end{abstract}

Keywords: ZnO nanoparticles, epoxy poly (dimethylacrylamide) copolymer, thermal stability, $\mathrm{pH}$ and humidity responsiveness

Cite this Article as: V. Sorna gowri , Sunil Kumar Sanghi, S.S.Amritphale, Noémia Carneiro, Pedro Souto and Sandra Ventura (2016), " Synthesis and Characterization of Poly (N- Isopropylacrylamide) ZnO Nanocomposites for Textile Applications", Journal of Research in Nanotechnology, Vol. 2016 (2016), Article ID 211103, DOI: 10.5171/2016.211103 


\section{Introduction}

Stimuli -responsive polymers are the polymers which undergo reversible volume change in response to small variation in external stimuli such as temperature, $\mathrm{pH}$ and ionic strength. These stimuli responsive polymers are currently being considered as an option in obtaining stimuli response textile materials (Liu and $\mathrm{Hu} 2005$ ). Poly ( $\mathrm{N}$-isopropylacryl amide) PNIPAM is a wellknown thermo responsive polymer which shows a coil - globule transition at lower critical solution temperature (LCST) at around $32^{\circ} \mathrm{C}$ (Schild 1992). This character is particularly useful in textile applications because this falls between body temperature and room temperature.

A multifunctional thermo responsive polymer nanocomposite can be prepared by the combination of inorganic oxide nanoparticles with PNIPAM to form PNIPAM nanocomposites. UV absorbers have been used to protect textile surfaces. Simultaneously, the interest in the application of nanotechnology in the textile industry has increased rapidly and has been the subject of several studies aiming to develop new finishing approaches to improve functional properties. For example, the nanoparticles of zeolites have led to better UV and antimicrobial protection of cotton and polyester fabric (Grancariæ and Tarbuk 2000; Grancariæ et al., 2006; Grancariæ et al., 2007). Now Ag has been used to impart antibacterial properties (Lee et al., 2003) nanoTiO 2 is used for UV blocking and self-cleaning properties (Xin et al., 2004; Fei et al., 2006; Qi et al., 2007) and nano $\mathrm{ZnO}$ is used for antibacterial and UV blocking properties (Wang et al., 2004; Baglioni et al., 2003; Wang et al., 2005; Vigneshwaran et al., 2006). Imparting functional properties i.e antibacterial and UV protection by using nanoparticles was done earlier by researchers (Ibrahim et al., 2013; 2012; 2010). Inorganic UV blockers are preferable to organic UV blockers (Riva et al., 2006; Scalia et al., 2006) because inorganic absorbers such as zinc oxide are non toxic and chemically stable under exposure to both high temperature and UV radiations. Nanoparticles have large surface area to volume ratio. The proper dispersion and homogeneous distribution of nanoparticles via coating layer yields more effective UV blocking with less material than a coating modified with coarse materials (Yadav et al., 2006). Furthermore these coatings are transparent /colorless which are important for the product appearance. If the employed particles exhibit particle size below $50 \mathrm{~nm}$ no light scattering within the coating occurs, guaranteeing transparency. $\mathrm{ZnO}$ is widely used in different areas because of its unique photocatalytic, electrical, electronic, optical, dermatological and antibacterial properties ( Turkoglu and Yener 1997; Pan et al., 2001; Arnold et al., 2003; Sawai 2003; Xiong et al., 2003; Tang et al., 2006; Sorna et al., 2010 ).

The aim of the present study is to develop a multifunctional polymer nanocomposite system that could be applied to textiles, providing conditions of effective bonding for obtaining permanent effects.

\section{Experimental}

\section{Materials}

Zinc nitrate (98\% purity) was procured from Acros Organic, New Jersey, USA. Poly (isopropylacrylamide), PNIPAM, with molecular weight of $10205 \mathrm{~g} / \mathrm{mol}$ was purchased from Sigma Aldrich. Sodium hydroxide and deionised water, of laboratory grade, were obtained from indigenous sources.

\section{Synthesis of ZnO nanoparticles}

Zinc oxide nanoparticles were prepared from zinc nitrate solutions after neutralizing with sodium hydroxide to $\mathrm{pH}$ values of 12 . Conventional heating experiments were conducted on magnetic stirrer. When the reactions were completed, the solid and solution phases were separated by centrifugation and the solids were washed 
free of salts with deionized water (3X) and ethanol (2X). Then the white powder obtained was calcined at higher temperature and then grinded manually for uniformity of the powder.

\section{Preparation of PNIPAM ZnO nanocomposites}

Different concentrations of nanoparticles in distilled water are prepared by taking 0.2 , $0.4,0.6$, and $0.8 \mathrm{~g}$ of $\mathrm{ZnO}$ nanoparticles in $100 \mathrm{ml}$ of double distilled water and kept under sonification for 20 minutes. $4 \times 10^{3}$ $\mathrm{g} / \mathrm{L}$ of PNIPAM solution was prepared in double distilled water under sonification. Equal volumes of the above solutions are taken and kept under ultra sonification for 12 hours.

\section{Characterization of ZnO nanopartices and PNIPAM ZnO nanocomposites}

TGA analysis was carried out under $\mathrm{N}_{2}$ on a simultaneous thermal analyzer Mettler Toledo using heating rate of $20^{\circ} \mathrm{C} / \mathrm{min}$. The particle size and zeta potential was measured by dynamic light scattering using Malrvern system at temperature between 25 to $60^{\circ} \mathrm{C}$. The X-ray diffraction (XRD) pattern of nanoparticles was analyzed with X-ray diffractometer (Model: Bruker D8 Discover) using $\mathrm{Cu} \mathrm{K} \alpha$ radiation at wavelength $\lambda=$ $0.15406 \mathrm{~nm}$, scan range $2 \theta=20^{\circ}-90^{\circ}$, scanning rate $=0.02 \mathrm{deg} / \mathrm{s}$ (applied voltage $40 \mathrm{KV}$, current $20 \mathrm{~mA}$ ). Morphological analysis of the samples was done by Nova Nano SEM 430 and FTIR by ALPHA FT-IR Spectrometer.

Before the coating process, DBD (Dielectric Barrier Discharge) plasma treatment was used in order to try the improvement of the nanocomposite

adhesion/reactivity/durability conditions towards the cotton substrate. The atmospheric discharge was performed in a laboratorial prototype which is a patented model "Lisboa" developed by the partnership Softal/University of Minho working with variable power of discharge, velocity and number of passages for $0,5 \mathrm{~m}$ electrodes width.

The plasmatic dosage chosen was 2700 W.min. $\mathrm{m}^{-2}$, each side of the fabric, in accordance with the results of the hydrophilic character of the fabric evaluated by a wicking test in order to get optimized results of water diffusion and contact in the fabric surface.

For the coating of the cotton fabric with PNIPAM ZnO nanocomposite, the application process was the following:

- The cotton fabric was cut in samples of $70 \mathrm{~g}$ each, approximately;

- Then the samples were introduced in the solutions of $\mathrm{ZnO}$ - PNIPAM;

- The fabric solutions were homogenized for $30 \mathrm{~min}$ in the ultrasound apparel;

- When taking the samples of solution they were passed in foulard with pressure of 4,1 bar and velocity of $2,54 \mathrm{~m} / \mathrm{min}$;

- Finally, the samples are air dried.

\section{Determination of stimuli responsive properties}

In order to determine $\mathrm{pH}$-responsiveness of fabric material with incorporated nanocomposites, swelling properties were assessed by a gravimetric method. Fabric samples of dimensions $4 \mathrm{X} 4 \mathrm{~cm}$ were immersed in excess of hydrochloric acid solution ( $\mathrm{pH} 5$ ) or sodium hydroxide solution $(\mathrm{pH} 9)$ until the swelling equilibrium was attained. The weight of the wet sample was determined after removing the surface water by blotting with filter paper. The swelling percentage (AS) was calculated by the following formula. Where Ws is the weight of sample in swelling equilibrium, WD is the initial weight of dried sample. In order to determine the influence of humidity bon swelling properties of surface modified textile material, a Humidity chamber purchased from Bio Tech India was used. 
Fabric samples of dimensions $4 \mathrm{X} 4 \mathrm{~cm}$ were put in the climatic chamber under conditions of constant temperature and humidity percentage for one hour.
For calculating swelling percentage the above equation is used.

\section{Results and discussions}

FTIR and XRD of ZnO nanoparticles

$$
S=\frac{W_{S}-W_{D}}{W_{D}} \times 100
$$

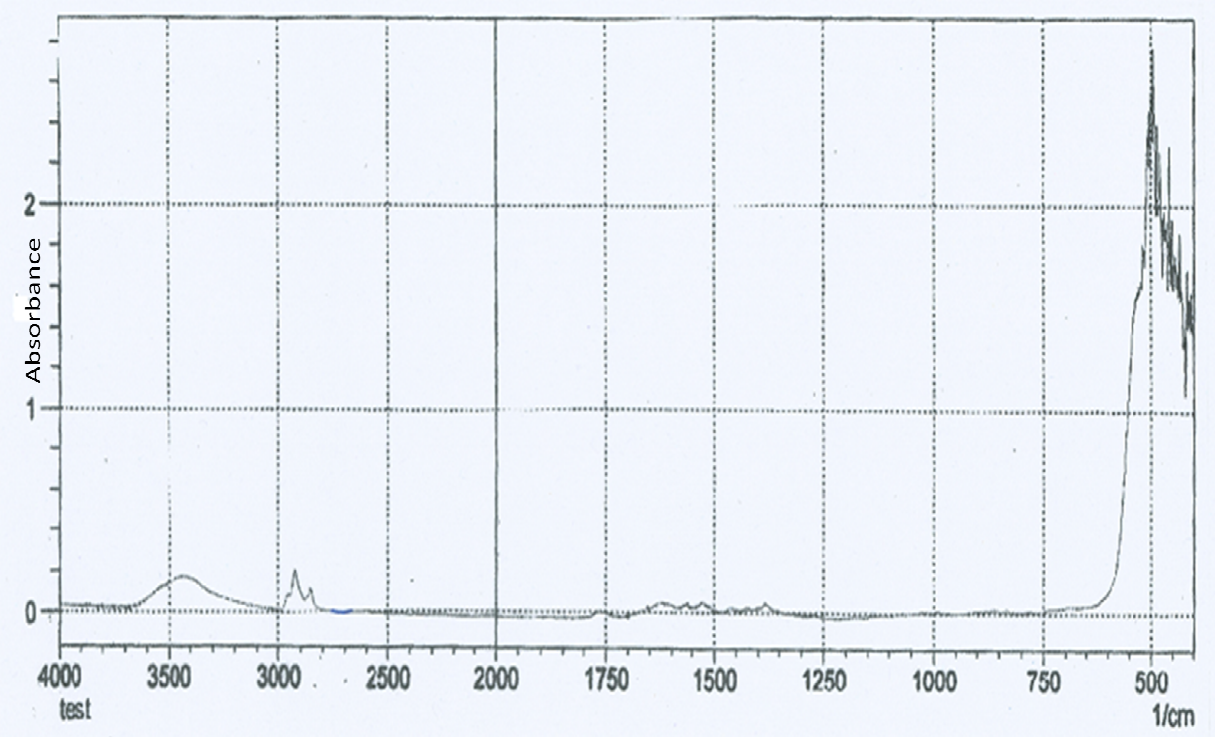

Figure 1: FTIR spectrum of the synthesized nano ZnO

Figure 1 shows the FTIR spectrum of the synthesized nano $\mathrm{ZnO}$. The spectrum shows clearly $\mathrm{ZnO}$ absorption band near $438 \mathrm{~cm}^{-1}$.
The peak at $3446 \mathrm{~cm}^{-1}$ corresponds to hydroxyl groups $(-\mathrm{OH})$ probably due to atmospheric moisture. 


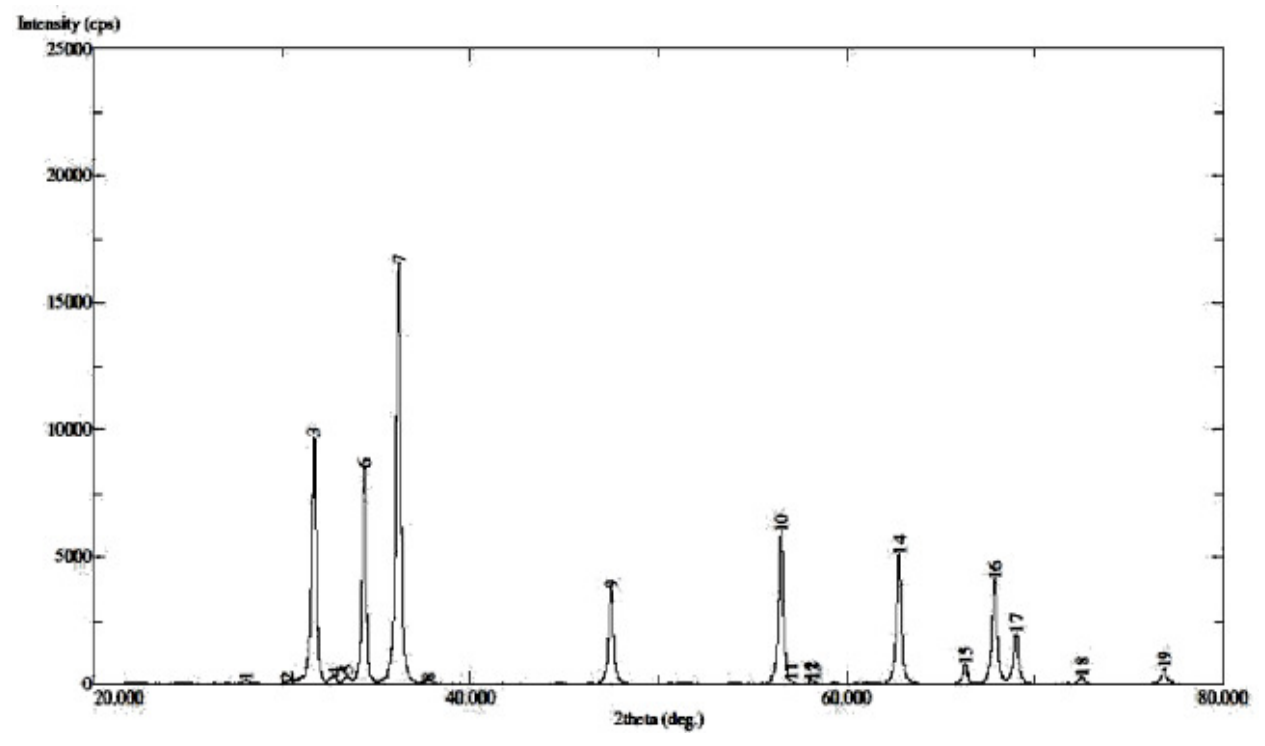

Figure 2: XRD pattern of ZnO

Figure 2 shows the XRD spectrum of the $\mathrm{ZnO}$ of the synthesized solid nanopowders. The spectrum shows well defined peaks typical of $\mathrm{ZnO}$ in the crystal structure of Zincite. The diffractogram of $\mathrm{ZnO}$ sample shows characteristic peaks of crystalline $\mathrm{ZnO}$ at $2 \theta$ values: $31.7,34.3,36.1,56.5,62.8,67.8$. This indicates the crystallinity of the synthesized solid. Traditionally the broadening of the peaks in the XRD patterns of solid is attributed to particle size effects.

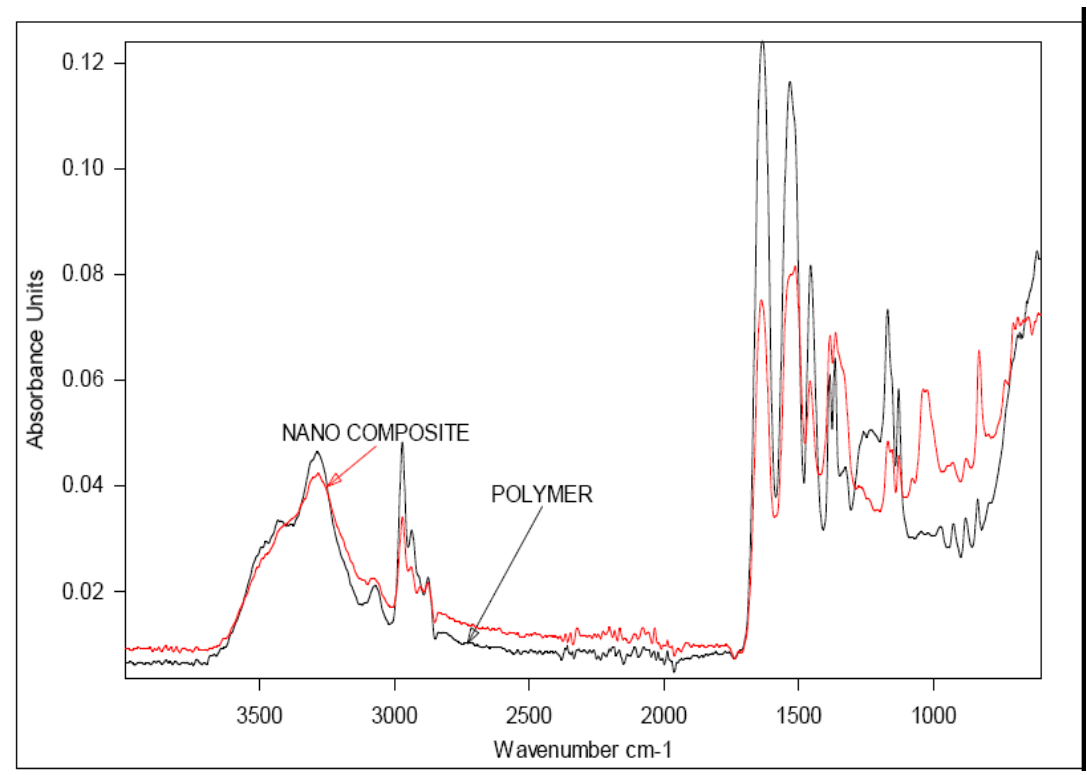

Figure 3: FTIR spectra of PNIPAM an PNIPAM - ZnO nanocomposite

V. Sorna gowri , Sunil Kumar Sanghi, S.S.Amritphale, Noémia Carneiro, Pedro Souto and Sandra Ventura (2016), Journal of Research in Nanotechnology, DOI: 10.5171/2016.211103 
FTIR spectroscopic studies were carried out for PNIPAM and PNIPAM - $\mathrm{ZnO}$ nanocomposite which are shown in figure 3 . The main characteristic peaks of PNIPAM are at 1080,1640 and $1540 \mathrm{~cm}^{-1}$ attributed to secondary amide $\mathrm{C}=0$ stretching and secondary amide $\mathrm{N}-\mathrm{H}$ stretching of PNIPAM chain (Fu et al., 2007; Suzuki et al., 2000; Pan YV, et al., 2001). Characteristic absorption bands are attributed to the asymmetric stretching of $\mathrm{C}-\mathrm{N}-\mathrm{C}$ at $1130-$ $1191 \mathrm{~cm}^{-1}$. The characteristic vibrations of $-\mathrm{OH}$ on the $\mathrm{ZnO}$ surface at $1024 \mathrm{~cm}^{-1}$ and $3450 \mathrm{~cm}^{-1}$ are also observed. The existence of $-\mathrm{OH}$ is important for the modification of $\mathrm{ZnO}$ particle surface with PNIPAM.

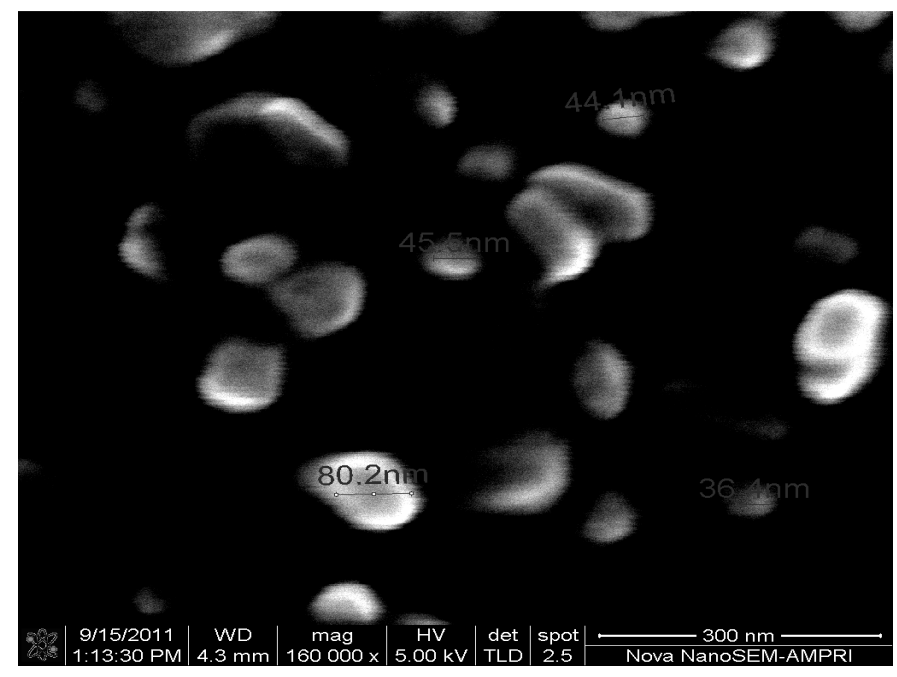

Figure 4: SEM micrographs of ZnO nanoparticles

\section{Morphology of $\mathrm{ZnO}$ nanoparticles and $\mathrm{ZnO}$ - PNIPAM nanocompsites}

Figure 4 displayed uniform particle morphology and each particle is approximately $80 \mathrm{~nm}$ in diameters. The particles are well dispersed. Meanwhile judging from figures $6,7 \& 8$ the dimensions of the aggregate particles are significantly larger than values in figure 5 due to the increase in the concentration of nanoparticles which leads to increase in aggregation of the nanoparticles at higher concentration. The $\mathrm{ZnO}$ nano particles display uniform particle morphology at lowest concentration. 


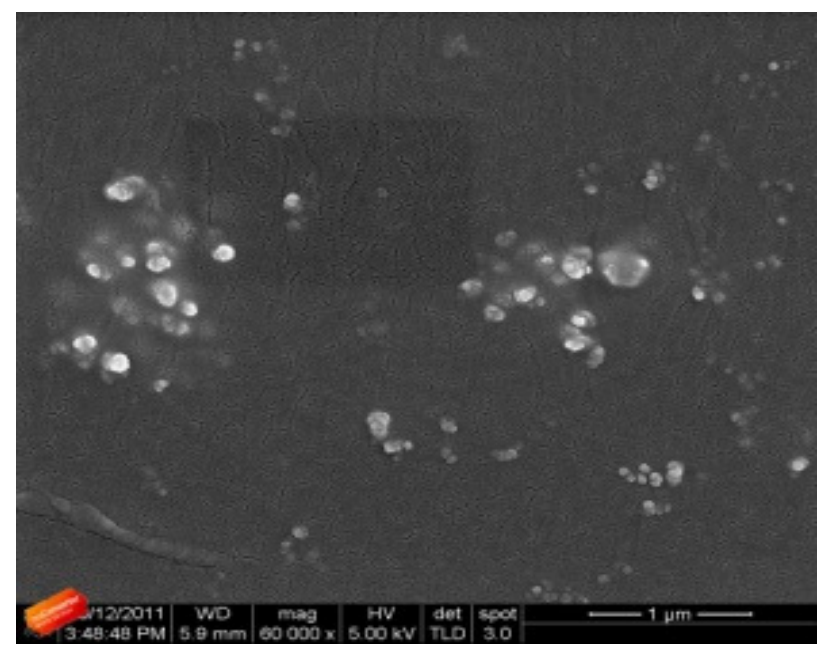

Figure 5: SEM micrographs of PNIPAM - ZnO nanocomposites with 0.2, \% Zn 0

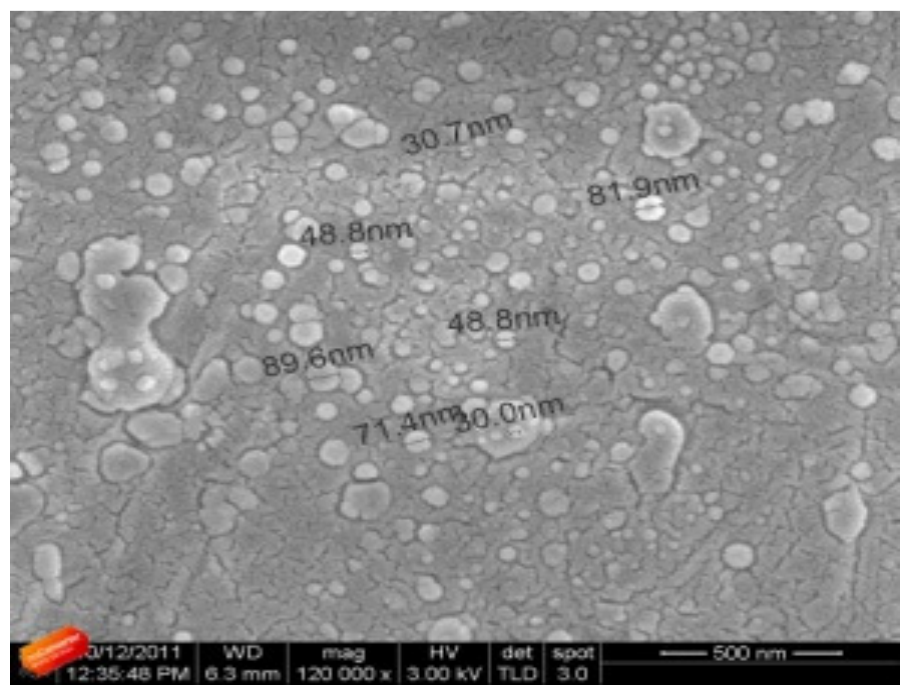

Figure 6: SEM micrographs of PNIPAM - ZnO nanocomposites with $0.4 \% \mathrm{Zn} 0$

V. Sorna gowri, Sunil Kumar Sanghi, S.S.Amritphale, Noémia Carneiro, Pedro Souto and Sandra Ventura (2016), Journal of Research in Nanotechnology, DOI: 10.5171/2016.211103 


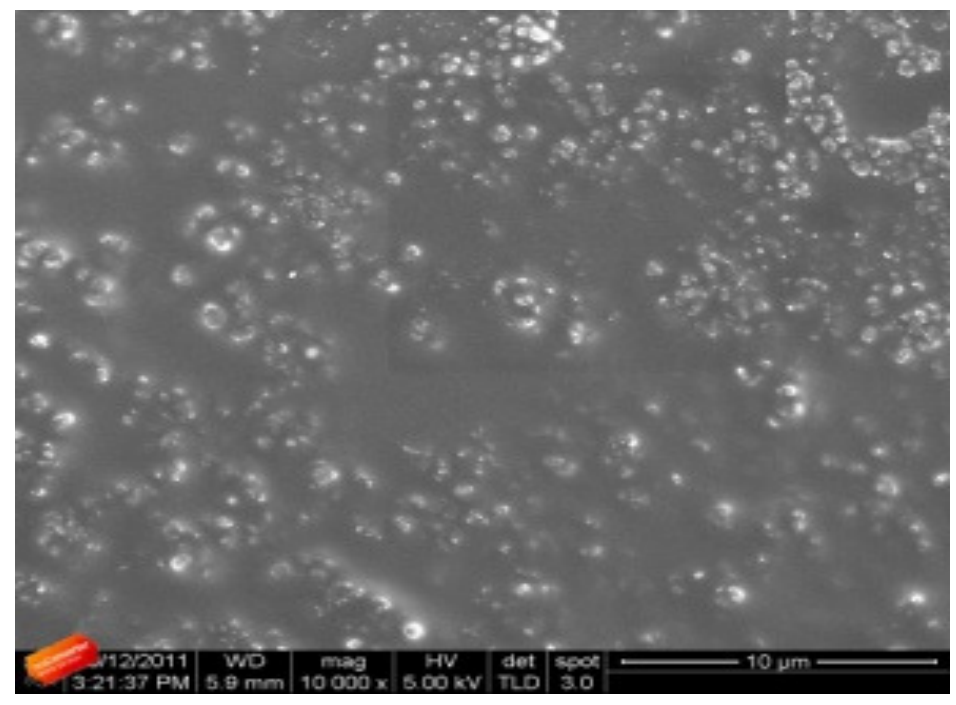

Figure 7: SEM micrographs of PNIPAM - ZnO nanocomposites with 0.6\% ZnO

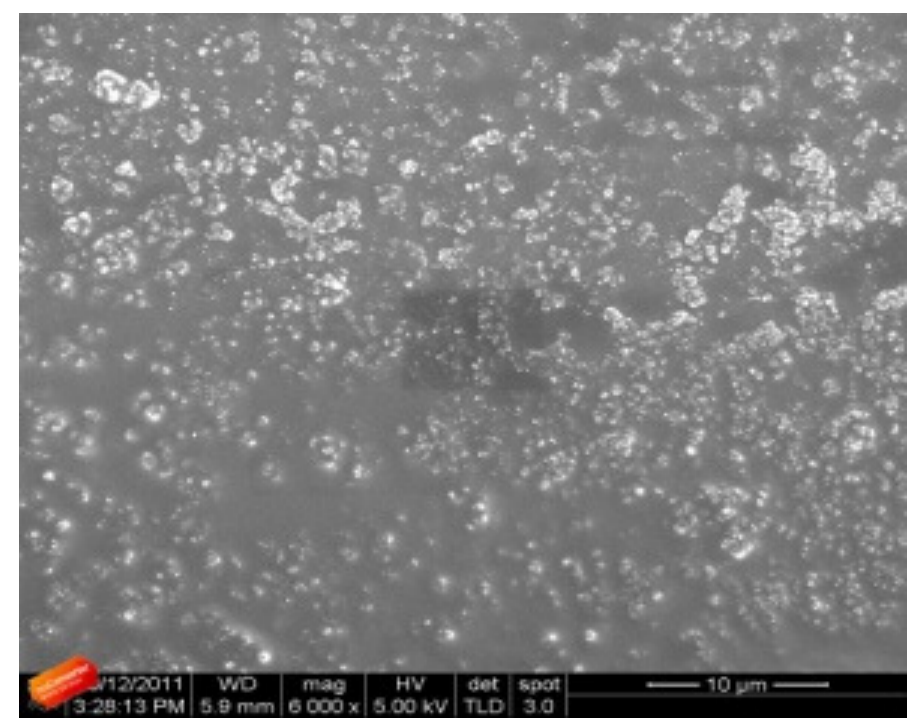

Figure: 8 SEM micrographs of PNIPAM - ZnO nanocomposites $0.8 \%$ ZnO

V. Sorna gowri, Sunil Kumar Sanghi, S.S.Amritphale, Noémia Carneiro, Pedro Souto and Sandra Ventura (2016), Journal of Research in Nanotechnology, DOI: 10.5171/2016.211103 
Thermal characterization of PNIPAM- ZnO nanocomposite

Thermal stability of the PNIPAM nanocomposite with different concentration of $\mathrm{ZnO}$ is shown in figure.9. Since inorganic species have good thermal stability, it is generally believed that the introduction of inorganic composites in to organic materials can improve their thermal stability. Thus, the increase in the thermal stability was attributed to the high thermal stability of $\mathrm{ZnO}$ and to the integration between the $\mathrm{ZnO}$ nanoparticles and polymer matrix. It is also noted worthy that PNIPAM and the nanocomposites decompose from temperature of $340-380{ }^{\circ} \mathrm{C}$ and thermal stability of nanocomposites was better than pure PNIPAM which was $300{ }^{\circ} \mathrm{C}$ ( 26).

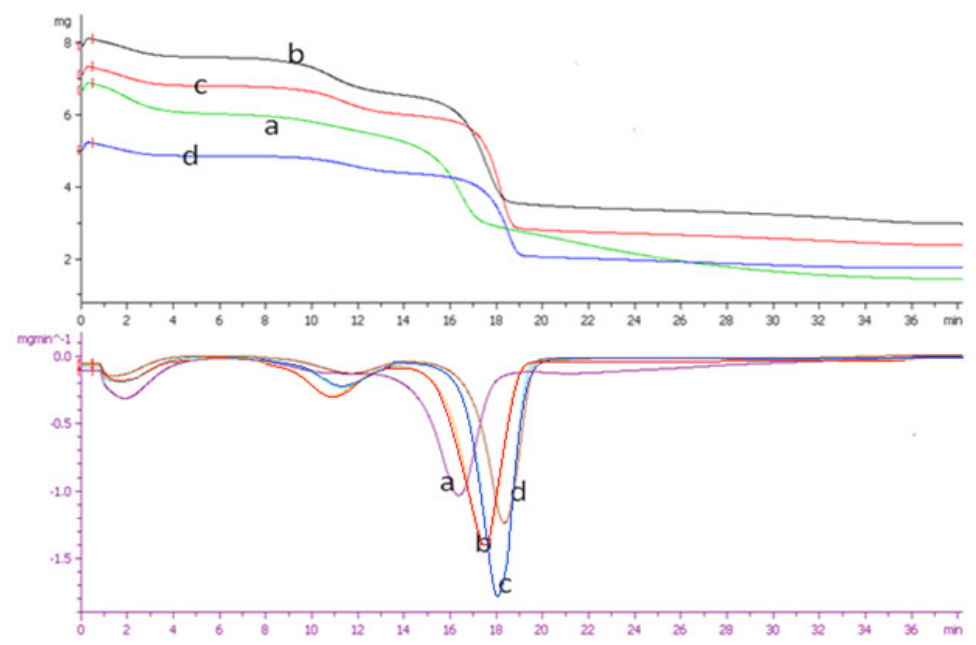

Figure 9: Thermal analysis of PNIPAM - ZnO nanocomposites with concentration of $0.2(\mathrm{~A}), 0.4(\mathrm{~B}), 0.6(\mathrm{C})$, and $0.8(\mathrm{D}) \% \mathrm{ZnO}$

\section{Particle size distribution}

Figure 10 shows a typical nanoparticles size distribution profile in nanocomposites with $0.2,0.4,0.6$ and $0.8 \% \mathrm{ZnO}$ in PNIPAM. It was found that the nanoparticles have narrow distribution of size. The $z$-average particle size and polydispersity indexes (PDI) were $716.7 \mathrm{~nm}(\mathrm{PDI}=0.741), 863.9$ $\mathrm{nm}(\mathrm{PDI}=0.909), 980.2 \mathrm{~nm}(\mathrm{PDI}=0.946)$ and $1067 \mathrm{~nm}$ (PDI $=0.987$ ) for $0.2 \%, 0.4 \%$, and $0.6 \%$ and $0.8 \% \mathrm{ZnO}$ respectively. Slight increase in polydispersity index for the sample with $0.8 \% \mathrm{ZnO}$ was probably due to slight agglomeration of $\mathrm{ZnO}$ nanoparticles. It was also found that the mean particle size of the dispersion was increased with increasing $\mathrm{ZnO}$ content. The results were consistent with SEM observations. 


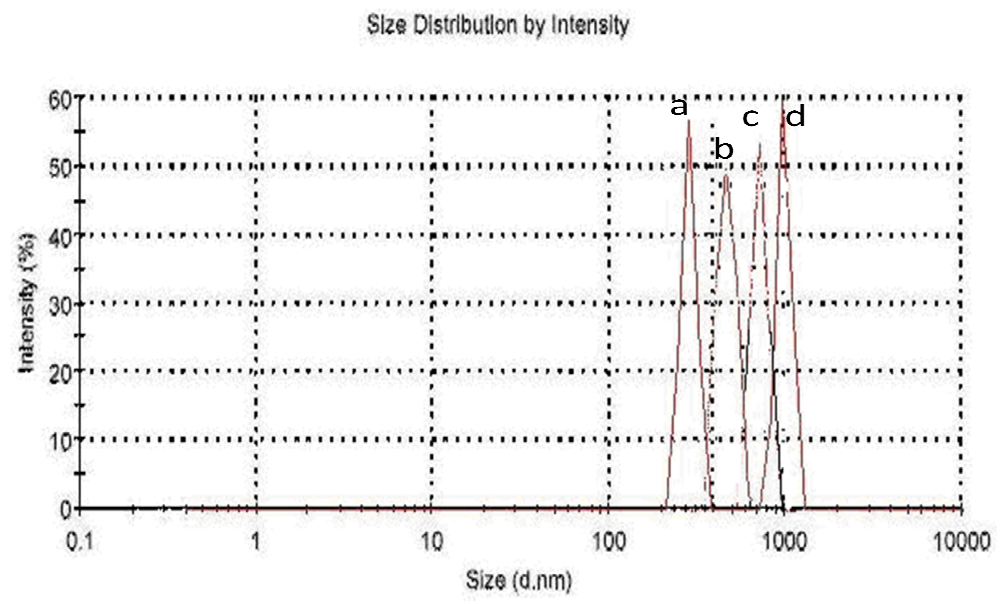

Figure 10: Typical size distribution profile of nanocomposite with

0.2(a), 0.4(b), 0.6(c) and 0.8(d) \% ZnO in PNIPAM

\section{Zeta potential analysis}

The zeta potential of the nanocomposites with different concentration of $\mathrm{ZnO}$ nanoparticles is shown in figure 11 . This -ve charge was attributed to PNIPAM. The _ve surface charge of the nanoparticles also illustrate that the PNIPAM was successfully coated on the surface of the $\mathrm{ZnO}$ nanoparticle, being the zeta potential often used as an index of the magnitude of electrostatic integration between the nanoparticles and polymer matrix and thus is useful measure to find interaction between PNIPAM and $\mathrm{ZnO}$ nanoparticles. The value of zeta potential results how the PNIPAM can adsorb onto the $\mathrm{ZnO}$ nanoparticles and impart - ve charge to the surface of the nanoparticles.

Zeta Potential Distribution

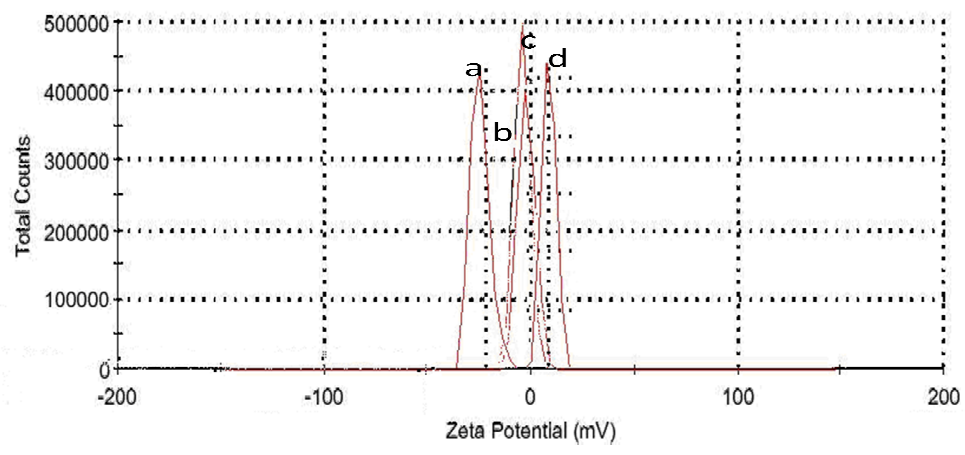

Figure 11: The zeta potential of the nanocomposites with $0.2(\mathrm{a}), 0.4(\mathrm{~b}), 0.6(\mathrm{c})$ and $0.8(\mathrm{~d}) \%$ concentration of $\mathrm{ZnO}$ nanoparticles

V. Sorna gowri, Sunil Kumar Sanghi, S.S.Amritphale, Noémia Carneiro, Pedro Souto and Sandra Ventura (2016), Journal of Research in Nanotechnology, DOI: 10.5171/2016.211103 


\section{pH dependence of swelling percentage $S$}

In order to determine $\mathrm{pH}$ responsiveness of the fabric material with incorporated nanocomposites, swelling properties were assessed by gravimetric method (Table 1) the same trails were run on untreated, DBD treated samples.

Table 1: \% Swelling (S)

\begin{tabular}{|l|c|c|}
\hline Sample & pH 5 & pH 9 \\
\hline Control & 52.25 & 33.81 \\
\hline Control + PNIPAM & 54.28 & 38.62 \\
\hline Control+ DBD & 53.38 & 34.25 \\
\hline PNIPAM+DBD & 55.706 & 39.50 \\
\hline PNIPAM+0.2\% Zn0 & 55.18 & 39.00 \\
\hline $\begin{array}{l}\text { PNIPAM+DBD+0.2\% } \\
\text { Zn0 }\end{array}$ & 69.02 & 57.88 \\
\hline PNIPAM+0.4\% Zn0 & 65.40 & 53.38 \\
\hline $\begin{array}{l}\text { PNIPAM+DBD+ 0.4\% } \\
\text { ZnO }\end{array}$ & 63.50 & 47.73 \\
\hline PNIPAM+0.6\% Zn0 & 60.94 & 46.87 \\
\hline $\begin{array}{l}\text { PNIPAM+DBD+ 0.6\% } \\
\text { ZnO }\end{array}$ & 58.82 & 45.92 \\
\hline PNIPAM+0.8\% Zn0 & 58.52 & 46.94 \\
\hline $\begin{array}{l}\text { PNIPAM+DBD+ 0.8\% } \\
\text { Zn0 }\end{array}$ & 57.52 & 43.25 \\
\hline
\end{tabular}

The DBD treatment made the fabric hydrophilic and there is slight increase in the swelling properties after DBD treatment. Incorporation of PNIPAM nanocomposites to fabric caused significant changes in swelling behavior. In any case, in terms of difference of swelling between acidic and alkaline $\mathrm{pH}$, the most attractive results obtained with PNIPAM nanocomposites incorporated fabric samples. Swelling increase in acidic as well as alkali media which was expected behavior that could be attributed to the $\mathrm{pH}$ responsiveness of PNIPAM. The swelling effect increase after treatment with PNIPAM nanocomposites and the swelling values increases with increase of \% of nanoparticles in PNIPAM nanocomposites.

\section{Moisture Regain with relative Humidity (RH)}

As expected, since moisture concentration in air is the driving force for moisture absorption, the moisture regain $\mathrm{R}$ always increased with RH increase. 


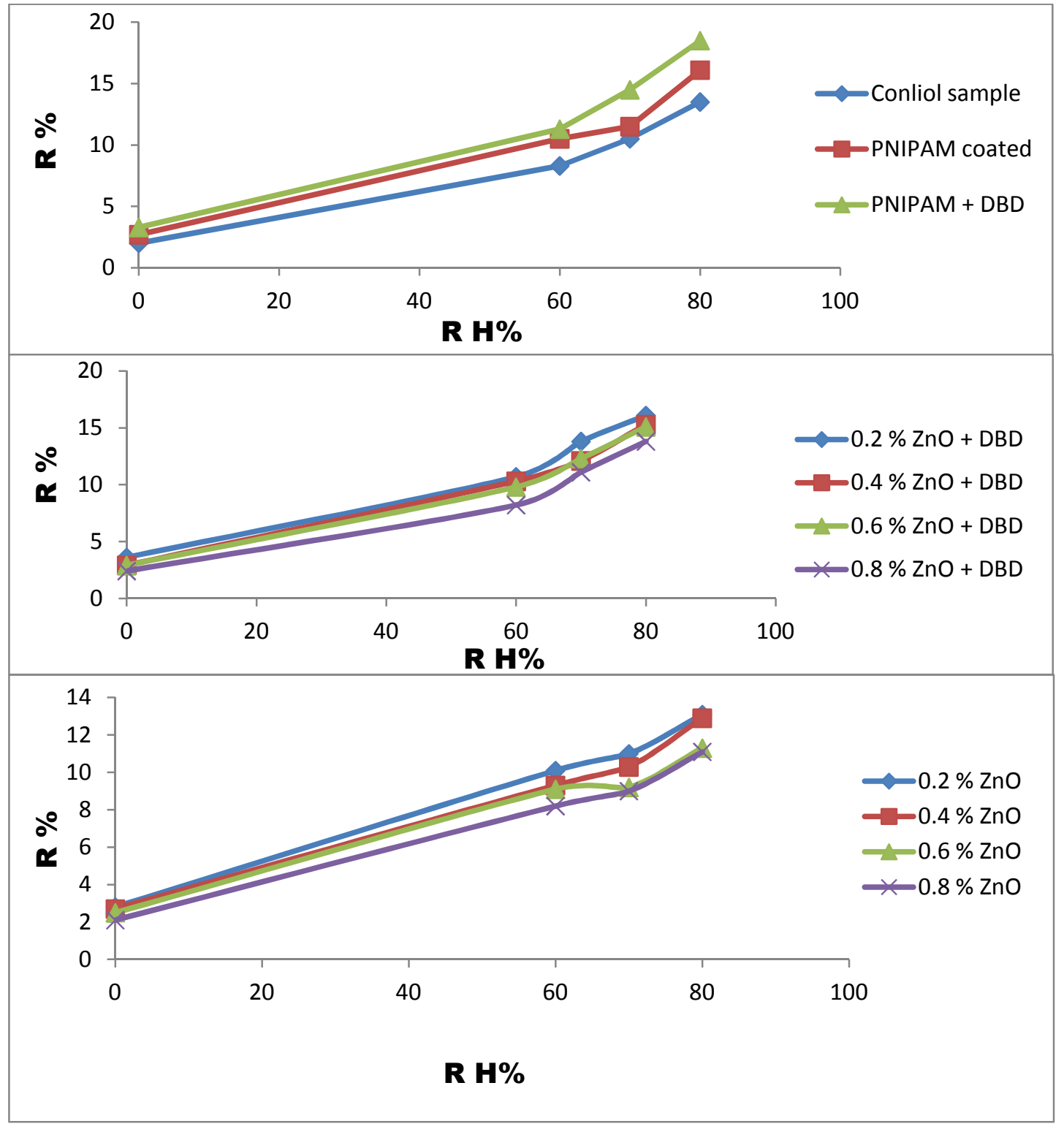

Figure 12: Moisture regain $R$ of the treated and untreated fabric measured at different humidity

When PNIPAM nanocomposite incorporated to DBD treated fabric, the moisture regain was slightly increased or stayed at similar value as compared with corresponding control samples except for higher values of $\mathrm{RH}$, where noticeable increase was observed.
In general, when dry fabric with incorporated PNIPAM nanocomposite is subjected to an environment containing moisture, both the fiber and the polymeric system absorb the moisture at rate that depends on a number of physical factors

V. Sorna gowri , Sunil Kumar Sanghi, S.S.Amritphale, Noémia Carneiro, Pedro Souto and Sandra Ventura (2016), Journal of Research in Nanotechnology, DOI: 10.5171/2016.211103 
initially the moisture uptake, the competition between the fiber and the polymer nanocomposite is the most important factor. Hence the polymer nanocomposite plays preferential role where the integration with moisture occur. This is also due to low crystallinity of polymer nano composite than the fabric. (Jocic, D. et al., 2009)

\section{Conclusions}

The preparation of nanocomposites in industrial scale is still difficult to achieve. There are many methods for their preparation, but a universal easy and efficient process allowing a perfect distribution of the inorganic particles in a polymer matrix is a challenge. This is mainly due to the difficulties in fulfilling all necessary requirements such as good compatibility and high degree of entanglement between polymer matrix and polymer chains attached to the surface of the inorganic particles. In this work we demonstrated that an excellent surface modification can be achieved by adsorption of copolymers as stabilizers on $\mathrm{ZnO}$ surface:

FT-IR studies confirmed that the polymer molecules chain was anchored on the surface of the $\mathrm{ZnO}$ nanoparticles.

FT-IR measurements showed that the adsorption of polymers on nanoparticles surface derived from the formation of hydrogen bond from the hydrophobic effects of substituents on nitrogen atom. These hydrophobic groups could hinder water molecules replacing the adsorbed polymer molecules and markedly improved the dispersion of $\mathrm{ZnO}$ nanoparticles in polymer. The improved interfacial interaction

\section{References}

1. Arnold, MS., Avouri, P., Pan, ZW. and Wang, ZL (2003)'Field- Effect transistors based on single semiconducting oxide nanobelts,' J Phys Chem, B 107, 659-663. between the particles and polymer enhanced the thermal properties.

The present study shows that inter phase chemical links between the $\mathrm{ZnO}$ and the polymer chain prevent the agglomeration of $\mathrm{ZnO}$ nanoparticles making their distribution more homogeneous in polymer as evidenced by SEM analysis.

It was also found that the mean particle size of the dispersion was increased with increasing $\mathrm{ZnO}$ content. The results were consistent with SEM observations. The value of zeta potential results how the PNIPAM can absorb on to the $\mathrm{ZnO}$ nano particles and impart - ve charge to the surface of the nano particles.

Incorporation of PNIPAM nanocomposite to the fabric was achieved by the batch method. Swelling behavior and moisture sorption analysis showed the fabric incorporation with PNIPAM nanocomposites present interesting $\mathrm{pH}$ and humidity responsiveness. These results prove that the concept of functional finishing of fabric by PNIPAM nanocomposites could lead to the development of a novel material with highly attractive features of responsiveness to the environmental stimuli.

With this new procedure, we have created a tool to obtain a broad range of new inorganic organic hybrid materials in a very easy way for textile applications.

\section{Acknowledgement}

The authors are grateful to Department of Science and Technology (DST), India and Fundação para a Ciência e a Tecnologia (FCT), Portugal for the financial support to this study.

2. Baglioni, PL., Dei, L., Fratoni, P., Lo Nostro, M. and Moroni, M.(2003) 'Preparation of nano- and micro-particles of group II and transition metals oxides and hydroxides and their used in the ceramic,

V. Sorna gowri , Sunil Kumar Sanghi, S.S.Amritphale, Noémia Carneiro, Pedro Souto and Sandra Ventura (2016), Journal of Research in Nanotechnology, DOI: 10.5171/2016.211103 
textile and paper industries,'Patent WO 2003082742

3. Fei, B., Deng, Z., Xin,JH., Zhang, Y. and Pang, G. (2006) 'Room temperature synthesis of rutile nanorods and their applications on cloth,'Nanotechnology, 17, 1927-1931.

4. Fu, Q., Rama Rao, G., Ward., V, Lu, T.L. and Lopez, G. P. (2007). 'Thermoresponsive transport through ordered mesoporous silica/PNIPAAm copolymer membranes and microspheres,' Langmuir, Vol. 23, 170-174 ISSN: 0743-7463.

5. Gil, SS., Gyu, L. and Jin-Hae, C.(2003) 'Synthesis and LCST behavior of thermoresponsive poly $(\mathrm{N}-$ iso propyl acrylamide) - clay nanocomposites,' J. Ind. Eng. Chem., 9 (1), 58 - 62.

6. Grancariæ, AM., Markoviæ, L. and Tarbuk, A. (2007) 'Active multifunctional cotton treated with zeolite nanoparticles,' Tekstil, 56, 543-553.

7. Grancariæ, AM., Tarbuk, A., Dumitrescu, I. and Bišæan, J. (2006) 'UV protection of pretreated cotton - influence of fwa'sfluorescence,' AATCC Review, 6, 40-46.

8. Grancariæ, AM. and Tarbuk, A. (2009) 'EDA modified pet fabric treated with activated natural zeolite nanoparticles,'Materials Technology, 24, 5863.

9. Ibrahim, NA., Eid, BM., Abd El-Aziz, E. and Abou Elmaaty T.M. (2013) ' Functionalization of Linen/Cotton Pigment Prints Using Inorganic Nano Structure Materials', Carbohydrate Polymers, 97, 537545.

10. Ibrahim, NA., Eid, BM. and El-Batal,H. (2012) 'A Novel Approach for Adding Smart Functionalities to Cellulosic Fabrics', Carbohydrate Polymers, 87, 744-751.

11. Ibrahim, NA., Refaie, R. and Ahmed,A.F. (2010) 'Novel Approach for Attaining Cotton
Fabric with Multi Functional Properties', Journal of Industrial Textiles, 40 (1), 65-83. 12. Lee, HJ., Yeo, SY. and Jeong, H. (2003) 'Antibacterial effect of nanosized silver colloidal solution on textile fabrics,' J Mater Sci., 38, 2199-2204.

13. Liu, B. and Hu, J. (2005) 'The application of temperature-sensitive hydrogels,' Fibres \& Textiles in Eastern Europe, 13(6), 45-49.

14. Pan, YV., Wesley, RA., Luginbuhl, R., Denton, DD. and Ratner, B.D. (2001') 'Plasmapolymerized $\mathrm{N}$-isopropylacrylamide: Synthesis and characterization of a smart thermally responsive coating 'Biomacromolecules, 2, 32-36.

15. Pan, ZW., Dai, Z.R. and Wang, Z.L. (2001) 'Nanobelts of semiconducting oxides,' Science, 291, 1947-1949.

16. Qi, K., Chen, X., Liu, Y., Xin, JH., Mak, CL. and Daoud, W.A. (2007) 'Facile preparation of anatase/SiO2 spherical nanocomposites and their application in self cleaning textiles,'J Mater Chem., 17, 3504-3508.

17. Riva, AI., Algaba, M. and Pepio, M. (2006) 'Action of a finishing product in the improvement of the ultraviolet protection provided by cotton fabrics. Modelisation of the effect Cellulose, 13 , 697-704

18. Sawai, J. (2003) 'Quantitative evaluation of antibacterial activities of metallic oxide powders $(\mathrm{ZnO}, \mathrm{MgO}$ and $\mathrm{CaO})$ by conductimetric assay,' J Microbiol Methods, 54, 177-182.

19. Scalia, SR., Tursilli, A., Bianchi, P., Lo Nostro, Bocci, E., Ridi, F. and Baglioni, P. (2006) 'Incorporation of the sunscreen agent, octyl methocycinnamate in a cellulosic fabric grafted withb-cyclodextrin,' Int $J$ Pharm, 308, 155-159.

20. Schild, HG. (1992) 'Poly(Nisopropylacrylamide): experiment, theory and application,' Prog. Polym. Sci., 17, 163249.

V. Sorna gowri, Sunil Kumar Sanghi, S.S.Amritphale, Noémia Carneiro, Pedro Souto and Sandra Ventura (2016), Journal of Research in Nanotechnology, DOI: 10.5171/2016.211103 
21. Sorna Gowri, V., Luís , A., Maria Teresa, PA., Noémia, CP., Pedro Souto, A., Maria Fátima, E. and Sanghi , SK. (2010) 'Functional finishing of polyamide fabrics using ZnO-PMMA Nanocomposites', Journal of Materials Science, 45, 2427-2435.

22. Suzuki, K., Yumura, T., Mizuguchi, M., Tanaka, Y., Chen, C.W. and Akashi, M.(2000) 'Poly(N-isopropylacrylamide)-grafted silica as a support of platinum colloids: Preparation method, characterization, and catalytic properties in hydrogenation ,'J.Applied Polymer Sci. , 77, 2678-2684.

23. Tang, E., Cheng, G., Pang, X., Ma, X. and Xing, F. (2006) 'Synthesis of nano$\mathrm{ZnO} /$ poly(methylmethacrylate) composite microsphere through emulsion polymerization and its UV shielding property,' Colloid Polym Sci, 284, 422- 428.

24. Turkoglu, MS. and Yener, S. (1997) 'Design and in vivo evaluation of ultrafine inorganic-oxide-containing-sunscreen formulations,' Int J Cosmet Sci ,19, 193-201.

25. Vigneshwaran, N., Kumar S., Kathe, AA., Varadarajan, PV. and Prasad, V. (2006) 'Functional finishing of cotton fabrics using zinc oxide-soluble starch nanocomposites,' Nanotechnology, 17(20), 5087-5095.

26. Wang, R.H., Xin, J.H. and Tao, X.M. (2005) 'UV-blocking property of dumbbellshaped ZnO crystallites on cotton fabric,' Inorg Chem, 44(11), 3926-3930.

27. Wang, R.H, Xin, J.H., Tao, X.M. and Daoud, W.A. (2004) 'ZnO nanorods grown on cotton fabrics at low temperature,' Chem Phys Lett, 398(18), 250-255.

28. Xin, J.H., Daoud, W.A. and Kong, Y.Y .(2004) 'A new approach to UV-blocking treatment for cotton fabrics,' Text Res J., 74(2), 97-10.

29. Xiong, M., Gu, G., You, B. and $\mathrm{Wu}, \mathrm{L}$. (2003) 'Preparation and characterization of poly(styrene butylacrylate) latex/nano-ZnO nanocomposites,' J Appl Polym Sci., 90(7), 1923-1931.

30. Yadav, A., Prasad, V., Kathe, A.A., Raj, S., Yadav, D., Sundaramoorthy, C. and Vigneshwaran, N. (2006) 'Functional finishing in cotton fabrics using zinc oxide nanoparticles,' Bull Mater Sci ,29(6), 641645.

V. Sorna gowri , Sunil Kumar Sanghi, S.S.Amritphale, Noémia Carneiro, Pedro Souto and Sandra Ventura (2016), Journal of Research in Nanotechnology, DOI: 10.5171/2016.211103 